\title{
Accuracy of screening for gastric cancer using serum pepsinogen concentrations
}

\author{
F Kitahara, K Kobayashi, T Sato, Y Kojima, T Araki, M A Fujino
}

\begin{abstract}
BackgroundlAims-The characteristics of pepsinogen screening for gastric cancer were investigated to establish a suitable cut off point for identifying gastric cancer, using endoscopic diagnosis as the yardstick.

Subjects/Methods-Serum pepsinogen concentrations were measured in 5113 subjects who were also screened for gastric cancer by endoscopy. The cut off point for pepsinogen was determined using receiver operator characteristics curves. Results-The most suitable cut off point was a pepsinogen $I$ concentration of less than $70 \mathrm{ng} / \mathrm{ml}$ and a ratio of pepsinogen $I$ to pepsinogen II of less than 3.0. Using this cut off point, the sensitivity and specificity of pepsinogen screening for gastric cancer were $84.6 \%$ and $73.5 \%$ respectively. All cases of gastric cancer in patients with severe atrophic gastritis were detected. However, two of four cases of gastric cancer in patients with mild atrophic gastritis were overlooked. In subjects with mild atrophic gastritis, when gastric cancer arises within the fundic gland region, the size of the lesion determines whether it is possible to detect cancer by serum pepsinogen screening.

Conclusion-Pepsinogen screening has many advantages, including its suitability for combination with other screening methods because it is simple and inexpensive.

(Gut 1999;44:693-697)
\end{abstract}

Keywords: pepsinogen; gastric cancer; screening; cut off point; receiver operator characteristics curves; atrophic gastritis

T Sato

Y Kojima

M A Fujino

Health Care Centre, Yamanashi Koseiren, Yamanashi, Japan

K Kobayashi

Department of Radiology, Yamanashi Medical University, Yamanashi, Japan T Araki

Correspondence to: Professor M A Fujino, First Department of Medicine, Yamanashi Medical

University, 1110 Shimokato, Tamaho-cho,

Nakakoma-gun, Yamanash 409-38, Japan

Accepted for publication 10 November 1998
Gastric cancer is a leading cause of cancer death in many countries. ${ }^{1}$ The age adjusted mortality rate of gastric cancer has decreased in Japan because many gastric cancers are detected at an early stage by mass screening using barium meal photofluorography. ${ }^{23}$ The usefulness of gastric cancer screening by photofluorography has been recognised ${ }^{3-5}$ but several problems have been noted, such as limited accuracy ${ }^{6}$ and cost-effectiveness ${ }^{8}$ and the risks of $x$ ray exposure. ${ }^{9}$ Therefore, to improve the effectiveness of gastric cancer screening, serum pepsinogen (PG) assay has recently been introduced in Japan. ${ }^{10-13}$ As atrophic gastritis becomes more severe, normal gland function is lost and enzyme production is affected. PG, the precursor of pepsin, exists as two main types, I (PG I) and II (PG II), both of which are produced by the chief and mucus neck cells in the gastric fundus. PG II, but not PG I, is produced by the pyloric glands in the antrum and Brunner's glands in the proximal duodenum. As gastritis progresses, mild inflammation leads to elevated concentrations of PG I and PG II in the circulation. As the severity of atrophy advances, chief cells are replaced by pyloric glands and the concentration of PG II remains increased, while the concentration of PG I decreases. Consequently, the ratio between the concentrations of PG I and PG II is greatly reduced. Thus serum PG concentration reflects the morphological and functional status of the gastric mucosa. ${ }^{14-16}$ Many gastric cancers develop in stomach mucosa affected by severe and extensive chronic atrophic gastritis. ${ }^{17}$ Therefore PG screening would enable the detection of subjects with extensive atrophic gastritis; such subjects have a high risk of developing gastric cancer. ${ }^{11-13}$

Previous reports on the accuracy of PG screening have compared it with photofluorography. ${ }^{12}{ }^{13}$ In this study, we investigated the characteristics of PG screening and the appropriate cut off points for identifying gastric cancer using receiver operator characteristics (ROC) curves, and compared PG screening with screening by endoscopy. Through this process, we were able to establish a sensitive and efficient screening method for the detection of gastric cancer using serum PG concentration. We also examined the characteristics of gastric cancers detected and missed by serum PG screening.

Subjects and methods

Endoscopy and assay of serum PG concentration were performed in 5113 subjects who were screened for gastric cancer as part of a periodic health check at the Health Care Center, Yamanashi Koseiren in 1995. They consisted of 2456 men and 2657 women, with a mean age of 52.5 years. Blood samples for routine laboratory tests were taken after fasting, and aliquots of the separated sera were individually stored below $-20^{\circ} \mathrm{C}$ until serum PG concentrations were assayed using PG I and II Riabead Kits (Dinabot Co Ltd, Tokyo, Japan), a modified radioimmunoassay method which has been described previously. ${ }^{18-20}$

Several determinations of suitable cut off points for screening for gastric cancer have been performed previously, and the subsequent results compared with findings from

Abbreviations used in this paper: PG, pepsinogen; I:II ratio, ratio between levels of pepsinogen I and pepsinogen II; ROC curve, receiver operator characteristics curve. 
Figure 1 Classification of chronic atrophic gastritis according to the location of the border between the fundic and pyloric gland regions by endoscopy: $C 1$, at the angular part of the lesser curvature; $C 2$, in the lower part of the lesser curvature; $C 3$, in the middle part of the lesser curvature; O1, all parts of the lesser curvature are pyloric; $\mathrm{O} 2$, the stage between $\mathrm{O} 1$ and $\mathrm{O} 3 ; \mathrm{O} 3$, all mucosa of the stomach is non-acid-secreting.

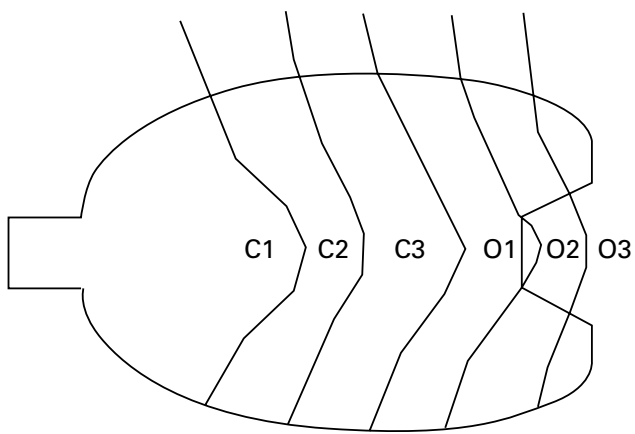

photofluorography. ${ }^{113}$ In this study we evaluated the sensitivity and specificity of a combinations of serum PG I concentration and I:II ratio (the ratio between the levels of pepsinogen I and pepsinogen II), serum PG I concentration alone, serum PG II concentration alone, and the I:II ratio alone, using ROC curves. We then determined a suitable cut off point for gastric cancer screening, compared with endoscopic diagnosis.

In Japan, many people voluntarily undergo a health check every year. Of the original 5113 subjects, 3138 had an endoscopy in 1996, and 2111 of these had another one in 1997. Six early gastric cancers were detected in 1996, and a further four in 1997. A retrospective assessment of the endoscopic images archived in 1995 showed that these 10 early gastric cancers were not overlooked by endoscopy in 1995. Therefore we also analysed the accuracy of a prospectively performed PG screening to confirm our cross sectional results.

We classified the stage of chronic atrophic gastritis in all gastric cancer cases detected by endoscopy according to guidelines published by Kimura and Takemoto ${ }^{15}$ (fig 1). For stage $\mathrm{C} 1$, the borderline between the fundic and pyloric regions is located at the angular part of the lesser curvature; for stage $\mathrm{C} 2$, the borderline is in the lower part of the lesser curvature aspect; and for stage C3, the borderline is in the middle part of the lesser curvature aspect. For stage $\mathrm{O} 1$, the entire lesser curvature aspect is pyloric. Stage O2 is between stages $\mathrm{O} 1$ and $\mathrm{O} 3$. In stage $\mathrm{O} 3$, the gastric mucosa is entirely nonacid-secreting. Stages $\mathrm{O} 1$ to $\mathrm{O} 3$ constitute the advanced stages of chronic gastritis.

We also studied the characteristics of the cancer cases detected and missed by PG screening, compared with the endoscopic classification of the stages of chronic atrophic gastritis.

STATISTICAL METHODS

Correlations between serum PG I concentration, PG II concentration, I:II ratio, and age were analysed. Differences in mean age, serum PG I concentration, PG II concentration, and I:II ratio between men and women were analysed by the Mann-Whitney U test. A probability (p) level of less than 0.05 was considered statistically significant.

\section{Results}

CONCENTRATION OF SERUM PG

PG I concentrations showed almost no variation with age in the 5113 subjects $(r=0.012$; p
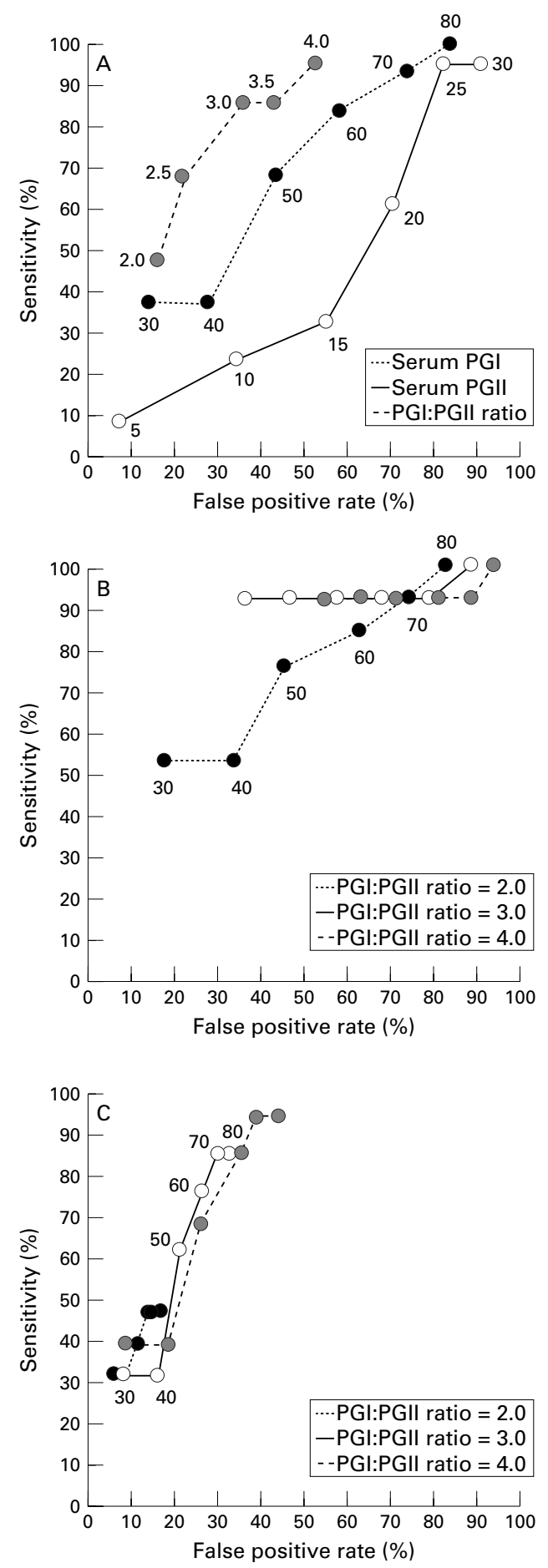

Figure 2 Receiver operator characteristics (ROC) curves generated with serum pepsinogen (PG) I concentrations alone, PG II concentrations alone, and I:II ratios alone $(A)$, various serum PG I concentrations or I:II ratios (B), the combination of various serum PG I concentrations and I:II ratios $(C)$, and by changing the serum PG I

concentration from 30 to $80 \mathrm{ng} / \mathrm{ml}$, the PG II concentration from 5 to $30 \mathrm{ng} / \mathrm{ml}$, and the I:II ratio from 2.0 to 4.0 intermittently. The following cut off points are found to be suitable: a I:II ratio of less than 3.0 alone $(A), a P G I$ concentration of less than $30 \mathrm{ng} / \mathrm{ml}$ or a I:II ratio of less than 3.0 (B), a PG I concentration of less than $70 \mathrm{ng} / \mathrm{ml}$ and a I:II ratio of less than $3.0(C)$.

$=0.3982)$. PG II concentrations increased significantly $(r=0.215 ; \mathrm{p}<0.001)$, and the I:II ratio decreased significantly $(r=-0.294$; $\mathrm{p}<0.001$ ) with advancing age. 


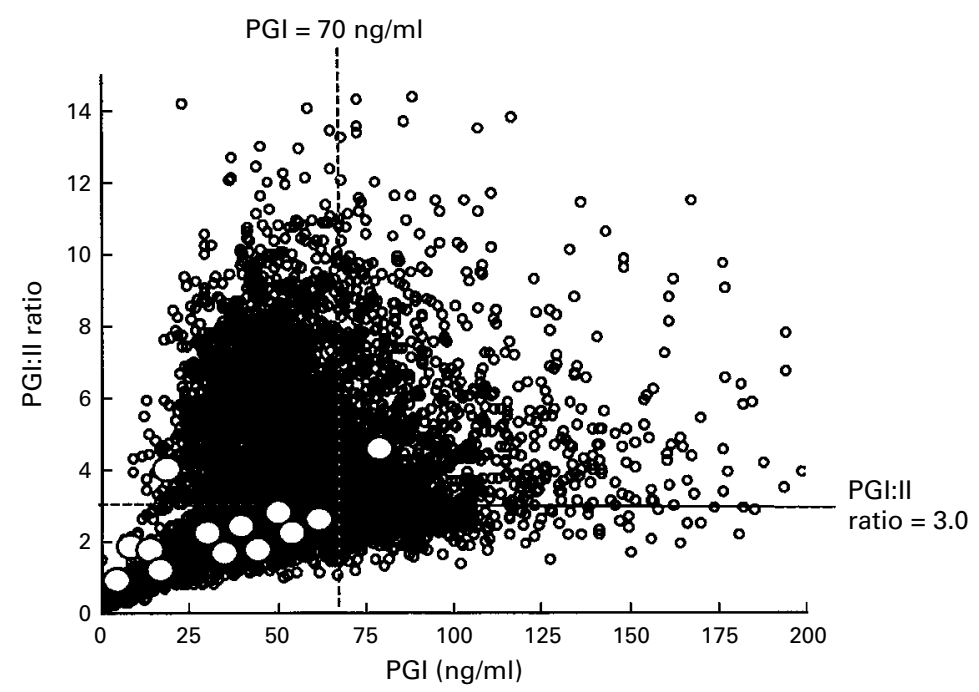

Figure 3 Distribution of serum pepsinogen (PG) I concentrations and I:II ratios in all subjects. White circles denote cases of gastric cancer. Of 13 gastric cancer cases, 11 would have been detected by the serum PG method, using a PG I concentration of less than 70 $\mathrm{ng} / \mathrm{ml}$ and a I:II ratio of less than 3.0 as the cut off point.

There was no significant difference in mean age between men and women $(p=0.6895)$. Men had significantly higher serum PG I concentrations than women $(\mathrm{p}<0.001)$. In contrast, we did not find any difference in mean serum PG II concentrations and I:II ratios between men and women (Mann-Whitney U test).

EVALUATION OF THE CUT OFF POINT

Thirteen cases of gastric cancer were detected $(0.25 \%)$. Of these, 11 were treated by surgical resection and two were excised by endoscopic surgery.

ROC curves were obtained by plotting a graph, in which the longitudinal axis showed sensitivity and the horizontal axis the false positive rate. The nearest point to the left upper corner shows the most suitable cut off point. The ROC curves generated with serum PG I concentrations, PG II concentrations, or I:II ratios alone, and various combinations of serum PG I concentrations and I:II ratios (changing the serum PG I concentration from 30 to $80 \mathrm{ng} / \mathrm{ml}$, the serum PG II concentration from 5 to $30 \mathrm{ng} / \mathrm{ml}$, and the I:II ratio from 2.0 to 4.0) were examined (fig 2). On the basis of these findings, the following cut off points were found to be suitable: a I:II ratio of less than 3.0 alone; a PG I concentration of less than 30 $\mathrm{ng} / \mathrm{ml}$ or a I:II ratio of less than 3.0 ; a PG I concentration of less than $70 \mathrm{ng} / \mathrm{ml}$ and a I:II ratio of less than 3.0.

The sensitivity and specificity of PG screening for gastric cancer were $84.6 \%$ and $67.2 \%$ for a I:II ratio less than 3.0 alone; $92.3 \%$ and $62.4 \%$ for a PG I concentration less than 30 $\mathrm{ng} / \mathrm{ml}$ or a I:II ratio less than $3.0 ; 84.6 \%$ and $73.5 \%$ for a PG I concentration less than 70 $\mathrm{ng} / \mathrm{ml}$ and a I:II ratio less than 3.0 respectively. Thus the most suitable cut off point for screening for gastric cancer was a PG I concentration of less than $70 \mathrm{ng} / \mathrm{ml}$ and a I:II ratio of less than 3.0.

ASSESSMENT OF GASTRIC CANCER CASES

Of the 13 gastric cancer cases detected by endoscopy, 11 would have been discovered by assay of serum PG concentrations, using a PG I concentration of less than $70 \mathrm{ng} / \mathrm{ml}$ and a I:II ratio of less than 3.0 as the cut off point (fig 3 ). The distribution of ages of the 13 cases varied from 53 to 75 years, with a mean (SD) of 66.2 (7.0) years (table 1$)$. There were eight men and five women. Nine of the gastric cancers were at an early stage, but four were detected at an advanced stage. There were six differentiated carcinomas and seven undifferentiated carcinomas. The cancers varied in size from 10 to $75 \mathrm{~mm}$ in diameter. Two lesions were localised within the mucosa, seven to the mucosa and submucosa, one invaded the muscularis propria, and three invaded the subserosa. The cancer was in the cardia in one subject, in the body in nine, and in the antrum in three. One subject had C1 stage gastritis, three had C2, three had O1, and six had O2. When we used the suitable cut off point (PG I concentration

Table 1 Characterisation of cases of gastric cancer detected by endoscopy

\begin{tabular}{|c|c|c|c|c|c|c|c|c|c|c|}
\hline Case & Age & $\operatorname{Sex}$ & Type & Pathology & $\begin{array}{l}\text { Size } \\
(\mathrm{mm})\end{array}$ & Depth & Locus & $P G I$ & I:II ratio & Stage \\
\hline 1 & 70 & M & IIa & $\begin{array}{l}\text { Well differentiated tubular } \\
\text { adenocarcinoma }\end{array}$ & 20 & Mucosa & Body & 13.63 & 1.13 & $\mathrm{O}_{1}$ \\
\hline 2 & 64 & M & IIa & $\begin{array}{l}\text { Well differentiated tubular } \\
\text { adenocarcinoma }\end{array}$ & 10 & Mucosa & Antrum & 48.36 & 2.23 & $\mathrm{O}_{1}$ \\
\hline 3 & 72 & $\mathrm{M}$ & IIa+IIc & $\begin{array}{l}\text { Well differentiated tubular } \\
\text { adenocarcinoma }\end{array}$ & 25 & Submucosa & Body & 8.57 & 1.67 & $\mathrm{O}_{1}$ \\
\hline 4 & 65 & $\mathrm{~F}$ & IIa & $\begin{array}{l}\text { Well differentiated tubular } \\
\text { adenocarcinoma }\end{array}$ & 15 & Submucosa & Body & 14.82 & 0.91 & $\mathrm{O}_{2}$ \\
\hline 5 & 68 & $\mathrm{~F}$ & IIa+IIc & $\begin{array}{l}\text { Well differentiated tubular } \\
\text { adenocarcinoma }\end{array}$ & 23 & Submucosa & Body & 40.92 & 2.17 & $\mathrm{O}_{2}$ \\
\hline 6 & 63 & $\mathrm{M}$ & IIa+IIc & $\begin{array}{l}\text { Moderately differentiated tubular } \\
\text { adenocarcinoma }\end{array}$ & 35 & Submucosa & Antrum & 77.55 & 4.02 & $\mathrm{C}_{2}$ \\
\hline 7 & 53 & $\mathrm{M}$ & IIc & Signet ring cell carcinoma & 35 & Submucosa & Body & 65.29 & 2.82 & $\mathrm{C}_{2}$ \\
\hline 8 & 75 & M & IIc & Signet ring cell carcinoma & 30 & Submucosa & Body & 56.56 & 2.38 & $\mathrm{O}_{2}^{2}$ \\
\hline 9 & 73 & $M$ & IIc & Signet ring cell carcinoma & 75 & Submucosa & Body & 13.03 & 3.77 & $\mathrm{C}_{1}^{2}$ \\
\hline 10 & 75 & M & B-2 & $\begin{array}{l}\text { Poorly differentiated tubular } \\
\text { adenocarcinoma }\end{array}$ & 20 & $\begin{array}{l}\text { Muscularis } \\
\text { propria }\end{array}$ & Cardia & 4.09 & 0.73 & $\mathrm{O}_{2}$ \\
\hline 11 & 55 & $\mathrm{~F}$ & B-4 & $\begin{array}{l}\text { Poorly differentiated tubular } \\
\text { adenocarcinoma }\end{array}$ & 60 & Subserosa & Body & 43.81 & 1.73 & $\mathrm{C}_{2}$ \\
\hline 12 & 66 & $\mathrm{~F}$ & B-3 & $\begin{array}{l}\text { Poorly differentiated tubular } \\
\text { adenocarcinoma }\end{array}$ & 50 & Subserosa & Antrum & 50.59 & 1.38 & $\mathrm{O}_{2}$ \\
\hline 13 & 61 & $\mathrm{~F}$ & IIc-adv. & Signet ring cell carcinoma & 15 & Subserosa & Body & 46.47 & 2.75 & $\mathrm{O}_{2}$ \\
\hline
\end{tabular}

Cases 6 and 9 have pepsinogen (PG) I concentration $>70 \mathrm{ng} / \mathrm{ml}$ or PG I:II $>3.0$.

Stage, stage of atrophic gastritis; M, male; F, female; B-2, Borrmann type 2; B-3, Borrmann type 3; B-4, Borrmann type 4; IIc-adv., advanced cancer resembling type IIc. 
Figure 4 Distribution of nine cases of gastric cancer in patients with severe atrophic gastritis. White lesions are differentiated and black are

undifferentiated. These nin cases were detected by serum pepsinogen (PG) screening for gastric cancer, using a serum PG I concentration of less than $70 \mathrm{ng} / \mathrm{ml}$ and $a$ I:II ratio of less than 3.0 as the cut off point. B-2, Borrmann type 2; B-3, Borrmann type 3; IIc-adv, advanced cancer resembling type IIc. Borderline, border between fundic and pyloric regions.

Figure 5 Distribution of four cases of gastric cancer in subjects with mild atrophic gastritis. The white lesions are differentiated, and the grey lesions are undifferentiated. Two of the four cases could not be detected by serum pepsinogen (PG) screening using a serum $P G I$ concentration of less than $70 \mathrm{ng} / \mathrm{ml}$ and $\mathrm{I}$ I:II ratio of less than 3.0 as the cut off point. B-4, Borrmann type 4. Borderline, borderline between fundic and pyloric regions.

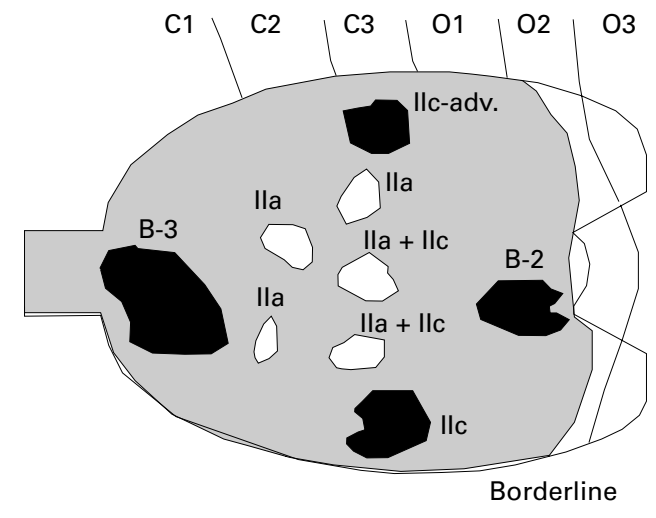

less than $70 \mathrm{ng} / \mathrm{ml}$ and I:II ratio less than 3.0) for gastric cancer screening, cases 6 and 9 were not detected (table 1).

Of the nine subjects with gastric cancer and $\mathrm{O} 1$ or $\mathrm{O} 2$ stage atrophic gastritis, three with type IIa and two with type IIa+IIc tumours had differentiated carcinoma. In contrast, the cases of type IIc, advanced cancer resembling type IIc, Borrmann type 2, and Borrmann type 3 tumours were undifferentiated (fig 4). The Borrmann type 2 cancer was in the cardia, the Borrmann type 3 and the two type IIa cancers were in the antrum, and the remaining five cancers were in the body. These nine cases were detected by serum PG screening for gastric cancer if the PG I concentration is set at less than $70 \mathrm{ng} / \mathrm{ml}$ and the I:II ratio at less than 3.0 as the cut off point.

Of the four cases of gastric cancer with $\mathrm{C} 1$ or C2 stage atrophic gastritis, the type IIa+IIc tumour was differentiated, while the Borrmann type 4 and the two type IIc cancers were undifferentiated (fig 5). When we used our cut off point for serum PG screening, the Borrmann type 4 and smaller type IIc cancers were detected, but the larger type IIc and the type IIa+IIc cancers were overlooked.

PROSPECTIVE ASSESSMENT OF PG SCREENING A total of 2111 subjects (41.4\%) underwent endoscopic screening in two consecutive years. Six early gastric cancers were detected in 1996, and a further four in 1997. No advanced cancer was detected. Of these 10 early gastric cancers, six were within the limit of a serum PG I concentration of less than $70 \mathrm{ng} / \mathrm{ml}$ and a I:II ratio of less than 3.0. If we investigated the accuracy of PG screening using this cut off point for

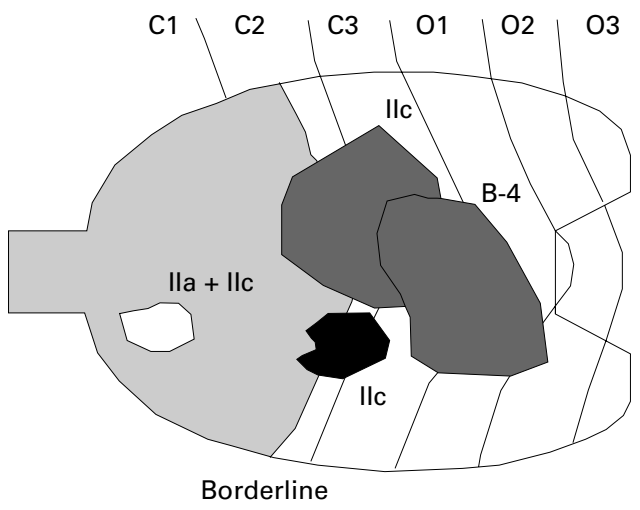

three consecutive years, the sensitivity, specificity, positive predictive value, and negative predictive value would be $73.9,72.7,2.94$, and $99.6 \%$ respectively.

\section{Discussion}

Several determinations of a suitable cut off point for gastric cancer screening have previously been made based on the findings of photofluorography. Stemmermann et $a l^{1}$ used a I:II ratio of less than 2.0 as the cut off point, to separate the subjects at high risk and those at low risk of developing gastric cancer. Miki et $a l^{12}$ suggested using a serum PG I concentration of less than $70 \mathrm{ng} / \mathrm{ml}$ and a I:II ratio of less than 3.0 as the cut off point. Kodoi et $a l^{13}$ suggested a serum PG I concentration of less than $50 \mathrm{ng} / \mathrm{ml}$ and a I:II ratio of less than 3.0 as the cut off point. As all these reports are based on comparisons with photofluorographic findings, their determinations of the false negative rate, sensitivity, specificity, and accuracy are not reliable. Therefore in this study, we determined a cut off point using endoscopic diagnosis as the yardstick.

The cut off point for gastric cancer screening can be determined by combining serum PG I concentrations and I:II ratios, or by determining serum PG I concentrations alone, serum PG II concentrations alone, or I:II ratios alone, as indicated by the finding that gastric cancer patients have lower concentrations of serum PG I and lower I:II ratios than normal. Based on ROC curves, if we determine a cut off point using serum PG I or PG II concentrations or I:II ratios alone, the sensitivity increases and the specificity decreases. When cut off points are determined by serum PG I concentration or I:II ratio, the sensitivity is superior but the specificity is inferior. The cut off point determined by combining serum PG I concentration and I:II ratio has superior specificity, and if we use a serum PG I concentration of less than $70 \mathrm{ng} / \mathrm{ml}$, the sensitivity is improved further. Using a cut off point of a serum PG I concentration of less than $70 \mathrm{ng} / \mathrm{ml}$ and a I:II ratio of less than 4.0 has superior sensitivity $(92.3 \%)$ for all gastric cancer cases but inferior specificity (62.4\%). A serum PG I concentration of less than $30 \mathrm{ng} / \mathrm{ml}$ or a I:II ratio of less than 3.0 also has the same superior sensitivity $(92.3 \%)$ but inferior specificity $(62.4 \%)$. The most suitable cut off point in screening for gastric cancer was found to be a PG I concentration of less than $70 \mathrm{ng} / \mathrm{ml}$ and a I:II ratio of less than 3.0. This cut off point provides a sensitivity of $84.6 \%$, a specificity of $73.5 \%$, a positive predictive value of $0.81 \%$, and a negative predictive value of $99.9 \%$, and prospective assessments provided a sensitivity of $73.9 \%$, a specificity of $72.7 \%$, a positive predictive value of $2.88 \%$, and negative predictive value of $99.6 \%$. The sensitivity of the prospective study was inferior to that of the retrospective study. The specificity of the prospective study was as good as that of the retrospective study. The positive predictive value of the prospective study was superior to that of the retrospective study. Our results agree with the cut off point suggested by Miki et al, ${ }^{12}$ but our study is based 
on a larger number of subjects, over a wider age range, and uses endoscopy as the yardstick. Therefore our results should be more reliable.

To detect gastric cancer, photofluorography using a $10 \times 10 \mathrm{~cm}$ sized film has been the traditional first screening step in Japan. The sensitivity of photofluorography has been found to be less than $40 \%$ in detecting early gastric cancer and greater than $90 \%$ in detecting advanced gastric cancer. ${ }^{22}$ Thus the sensitivity of PG screening for early gastric cancer is superior to that of photofluorography. The cost of PG screening is about half of that of photofluorography. ${ }^{12}$ Therefore PG screening for gastric cancer has many advantages over photofluorography: it is a very easy and inexpensive procedure, and there are no $x$ ray hazards.

In our study, it was possible to detect all cases of gastric cancer in patients with severe atrophic gastritis (stages $\mathrm{O} 1$ or $\mathrm{O} 2$ ) by serum PG screening using our cut off point. However, only two of four cases of gastric cancer in patients with mild atrophic gastritis were detected. These two cases were a Borrmann type 4 and a smaller type IIc lesion. In the Borrmann type 4 cancer, although the atrophic gastritis was mild, the cancer occupied a large part of the mid-body, the serum PG I concentration was decreased, and as a result the I:II ratio was also decreased. In the smaller type IIc cancer, as the cancer was limited to a small part of the fundic gland area, the serum PG I concentration and I:II ratio were only slightly decreased (about $65.3 \mathrm{ng} / \mathrm{ml}$ and 2.82 respectively).

Of the two cases we were unable to detect, as the larger type IIc cancer occupied a large part of both the pyloric and fundic gland regions, the serum PG I concentration $(13.0 \mathrm{ng} / \mathrm{ml})$ and serum PG II concentration ( $3.5 \mathrm{ng} / \mathrm{ml}$ ) both decreased. As a result, the I:II ratio did not decrease. The other missed type IIa+IIc cancer was confined to a small part of the pyloric gland, and because the atrophic gastritis was mild, the serum PG I concentration and I:II ratio did not decrease. A previous report suggested that gastric cancers such as this advance very slowly. ${ }^{22}$

As a result, in the subjects with severe atrophic gastritis it is possible to detect differentiated and undifferentiated carcinoma by serum PG screening, using a PG I concentration of less than $70 \mathrm{ng} / \mathrm{ml}$ and a I:II ratio of less than 3.0 as the cut off point. In the subjects with mild atrophic gastritis, when gastric cancer arises in the fundic gland region, the success of screening is determined by the size of the lesion. However, in subjects with mild atrophy, gastric cancer originating in the pyloric gland region is difficult to detect by serum PG screening.

In conclusion, with a suitable cut off point, screening for gastric cancer using serum PG concentrations can be effective. Certain lesions are very difficult to detect by photofluorography - for example, small or flat lesions and even large lesions located in the cardia or on the anterior wall ${ }^{6}$ _ but serum PG screening can identify non-ulcerated differentiated asymptomatic gastric cancer, irrespective of the size and location of the lesion. The PG method has many advantages, including its suitability for combination with other screening methods because it is simple and inexpensive.

1 Webb MP, Hengels JK, Moller $\mathrm{H}$, et al. The epidemiology of low serum pepsinogen A levels and an international association with gastric cancer rates. Gastroenterology 1994;107:1335-44.

2 Kabuto M, Imai H, Tsugane S, et al. Correlation between atrophic gastritis prevalance and gastric cancer mortality among middle-aged men in 5 areas in Japan. 7 Epidemiol 1993;3:35-9.

3 Fukao A, Hisamichi S, Sugawara N, et al. A case-control study on evaluating the effect of mass screening on decreasing advanced stomach cancer. Fournal of Gastroenterological Mass Survey 1987;75:112-16. (In Japanese.)

4 Fukao A, Tsubono Y, Tsuji I, et al. The evaluation of screening or gastric cancer in Miyagi Prefecture, Japan: a population-based case-control study. Int f Cancer 1995;60: populatic

5 Oshima A, Hirata N, Ubukata T, et al. The effect of a mass screening program in reducing stomach cancer mortality rate: evaluation with a case-control study design. Fournal of Gastroenterological Mass Survey 1986;73:47-52. (In Japanese.)

6 Hamahata M, Kusano K, Sibue T, et al. The close examination methods and the accuracy of gastric mass survey. Fournal of Gastroenterological Mass Survey 1993;98:3-8. (In Japanese.

7 Yoshida Y, Tamura K, Arisue T, et al. Study on controlling method of precision of the first screening of the gastric carcinoma mass survey. fournal of Gastroenterological Mass Survey 1992;97:51-8. (In Japanese.)

8 Iimura T, Takeno Y. Cost-effectiveness of mass screening for stomach cancer. Fournal of Gastroenterological Mass Survey 1988;79:94-100. (In Japanese.)

9 Maruyama T, Noda Y, Kumamoto Y. Estimation of frequency, population doses and stochastic risks in stomach mass screening examination in Japan. Nippon Acta Radiology 1987;47:971-82. (Japanese text with English abstract.

10 Kitahara F, Kashiwagi A, Kanai T, et al. A role of pepsinogen assay as the first cancer screening before screening by gastroscopy. Fournal of Gastroenterological Mass Survey 1996;116:42-8. (In Japanese.)

11 Miki K. Mass screening of stomach neoplasms by serum pepsinogen analysis. Fournal of the fapanese Society of Internal Medicine 1992;81:654-9.

12 Miki K, Ichinose M, Ishikawa KB, et al. Clinical application of serum pepsinogen I and II levels for mass screening to detect gastric cancer. $\mathcal{F p n}_{p} \mathcal{F}$ Cancer Res 1993;84:1086-90.

13 Kodoi A, Yoshihara M, Sumii K, et al. Serum pepsinogen in screening for gastric cancer. F Gastroenterol 1995;30:45260.

14 Samloff IM, Varis K, Ihamaki T, et al. Relationship among serum pepsinogen I, serum pepsinogen II and gastric mucosal histrogy: a study in relatives of patient with pernicious anemia Gastroenterology 1982;83:204-9.

15 Kimura K, Takemoto T. An endoscopic recognization of the atrophic border and its significance in chronic gastritis. Endoscopy 1969;1:87-97.

16 Sitas F, Smallwood R, Jewell D, et al. Serum anti-Helicobacter pylori IgG antibodies and pepsinogens $\mathrm{A}$ and $\mathrm{C}$ as serological markers of chronic atrophic gastritis. Cancer Epidemiology, Biomarkers and Prevention 1993;2:119-23.

17 Fukao A, Hisamichi S, Ohsato N, et al. Correlation between the prevalence of gastritis and gastric cancer in Japan. Cancer Causes and Control 1993;4:17-20.

18 Ichinose M, Miki K, Furihata C, et al. Radioimmunoassay of serum group I and group II pepsinogens in normal control subjects and patients with various disorders. Clin Chim Acta 1982;126:183-91.

19 Konishi N, Matsumoto K, Hiasa Y, et al. Tissue and serum pepsinogen I and II in gastric cancer identified using mmunohistochemistry and rapid ELISA. I Clin Pathol 1995; $48: 364-7$

20 Matsumoto K, Hashimoto K, Samori T, et al. Clinical significance of the measurement of serum pepsinogen group I and II by enzyme-linked immunosorbent assay. fapanese fournal of Clinical Pathology 1992;40:977-81. (In Japanese.)

21 Stemmermann GN, Samloff IM, Nomura AM, et al. Serum pepsinogens I and II and stomach cancer. Clin Chim Acta 1987;163:191-8.

22 Nishizawa Y. Investigation of mass survey for gastric cancer. fournal of Gastroenterological Mass Survey 1993;98:74-9. (In Japanese.) 